\title{
Consumo excessivo de oxigênio após atividade física - EPOC: uma breve explanação
}

\author{
Adriana Lima de Freitas ${ }^{1}$ \\ Antônio Felipe Corrêa Marangon ${ }^{2}$
}

\begin{abstract}
RESUMO - O consumo máximo de oxigênio ( $\mathrm{VO}_{2}$ máx.) envolve o engajamento completo do sistema aeróbico, que é o sistema energético predominante utilizado em exercícios com duração maior que 3 minutos. A adenosina trifosfato é a energia comum utilizada para todo o trabalho biológico que ocorre dentro das células. Além da ATP, o músculo esquelético possui outro fosfato altamente energético, chamado creatina fosfato, que pode ser utilizado na ressíntese de ATP. A principal função dos carboidratos consiste em funcionar como combustível energético, particularmente durante o exercício. A ingestão diária deve ser suficiente para manter as reservas corporais de glicogênio. Os lipídios representam a maior reserva nutritiva de energia química para a realização de trabalho biológico, incluindo a contração muscular. A desintegração protéica acima do nível de repouso ocorre durante o exercício com treinamento tanto de endurance quanto de resistência, em grau maior em que se acreditava antigamente. $\mathrm{O}$ valor do $\mathrm{VO}_{2}$ máx. expressa quantitativamente a capacidade individual para a ressíntese aeróbica do ATP. Assim, trata-se de fator importante para determinar a capacidade individual em realizar exercício de alta intensidade por mais de 4 ou 5 minutos. Em 1910, Hill publicou dados sobre o processo imediato da contração muscular não requerer consumo de oxigênio. Em 1913, proporcionou dados sobre o calor recuperado logo após a atividade física de contração muscular ser maior ou igual ao calor liberado durante a contração, mas somente se o oxigênio estivesse presente. Em 1922, estudou o metabolismo energético durante o exercício e a recuperação, explicando causas e conseqüências do EPOC.
\end{abstract}

Palavras-chave: gasto energético, EPOC, intensidade, exercício físico.

\footnotetext{
${ }^{1}$ Graduanda em Nutrição. E-mail: adrianalfreitas@ig.com.br UniCEUB - Brasília / DF

2 Professor de Fisiologia e Avaliação Nutricional do UniCEUB. E-mail: antonio.felipe@uniceub.br
} 


\title{
Expendure post exercise comsumption: EPOC
}

\begin{abstract}
The maximum consumption of oxygen ( $\mathrm{VO}_{2}$ máx.) involves the complete enrollment of the aeróbico system that is the used predominant energy system in exercises with bigger duration that 3 minutes. The adenosine trifosfato is the common energy used for all the biological work that occurs inside of the cells. Beyond the ATP, the esquelético muscle possesss another energy fosfato highly, creatina called fosfato, that can be used in ressíntese of ATP. The main function of the carboidratos consists of functioning as combustible energy, particularly during the exercise. The daily ingestion must be enough to keep the corporal reserves of glycogen. The lipídios represent the biggest nutritional reserve of chemical energy for the accomplishment of biological work, including the contraction muscular. The protéica disintegration above of the rest level occurs in such a way during the exercise with training of endurance how much of resistance, in a bigger degree where if it believed old. The value of the express VO2 máx. quantitatively the individual capacity for ressíntese aeróbica of the ATP. Thus being, one is about a factor important to determine the individual capacity in for more than carrying through an exercise of high intensity 4 or 5 minutes. In 1910, Hill published given indicating that the immediate process of the muscular contraction does not require oxygen consumption. In 1913, it provided given indicating that the heat recouped soon after the physical activity of muscular contraction was bigger or equal to the set free heat during the contraction, but if the oxygen was only present. In 1922, he approached the energy metabolism during the exercise and the recovery, explaining the causes and consequences of the EPOC.
\end{abstract}

Key words: EPOC, expendure post exercise comsumption, intensity, physical exercise.

Os carboidratos constituem importante fonte de energia para o metabolismo dos seres humanos. O glicogênio do músculo esquelético e a glicose sangüínea derivada do fígado são carboidratos disponíveis utilizados como fonte primária de combustível durante o exercício aeróbico e anaeróbico. A quebra do glicogênio muscular ou da glicose sangüínea que pode ser transformada em lactato contribui para a fadiga muscular durante exercícios de grande intensidade. A produção de lactato ocorre no músculo mesmo sob condições aeróbicas e acelera-se quando o suprimento de oxigênio é limitado (WOLINSKY, 2002). Durante exercício de curta duração, de leve a moderado, a captação de oxigênio da recuperação serve 
para refazer os fosfatos de alta energia depletados pelo exercício. Esse processo é rápido: é completado em poucos minutos. Durante exercício aeróbico de alta intensidade e de maior duração, a captação de oxigênio da recuperação pode continuar elevada por período consideravelmente maior, a esse processo damos o nome de EPOC - consumo excessivo de oxigênio após o exercício. Todos os sistemas fisiológicos ativados pelo exercício também necessitam de maior quantidade de oxigênio durante a recuperação. A dívida de oxigênio ou, mais precisamente, a captação de oxigênio da recuperação e o consumo excessivo de oxigênio após o exercício (EPOC) refletem tanto o metabolismo anaeróbico do exercício prévio quanto as ajustagens respiratórias, circulatórias, hormonais, iônicas e térmicas que ocorrem durante a recuperação (McARDLE,1998).

\section{Metabolismo}

\section{Aeróbico}

O consumo máximo de oxigênio $\left(\mathrm{VO}_{2}\right.$ máx.) ou a capacidade aeróbica máxima envolve o engajamento completo do sistema aeróbico. Este é o limite superior da habilidade de um indivíduo para consumir oxigênio. O sistema aeróbico é o sistema energético predominante utilizado em exercícios com duração maior que 3 minutos. (LIEBMAN; WILKINSON capud WOLINSKY,2002) A energia liberada na glicólise é rápida e não requer oxigênio, porém relativamente pouco ATP é ressintetizado por esse mecanismo. (McARDLE,1998)

O aumento na captação de oxigênio que resulta do exercício exibirá sempre certo retardo com relação ao dispêndio de energia, em virtude de demora inicial na produção de substrato oxidável com o qual o oxigênio possa combinar-se. $\mathrm{O}$ oxigênio torna-se importante nas reações subseqüentes de transferência de energia quando passa a funcionar como receptor de elétrons e combina-se com os hidrogênios gerados na glicólise, na oxidação beta dos ácidos graxos ou nas reações do Ciclo de Krebs. Entretanto, em alguns minutos de exercício submáximo, a produção de hidrogênio passa a ser proporcional à intensidade do exercício e à captação de oxigênio, em que se alcança ritmo estável no metabolismo aeróbico. O déficit de oxigênio pode ser considerado quantitativamente como a diferença entre o oxigênio total realmente consumido durante o exercício e o total que teria sido consumido se houvesse sido alcançado ritmo estável de metabolismo aeróbico desde o início. (McARDLE,1998)

O oxigênio da recuperação pode ser definido como a quantidade global de oxigênio consumida durante a recuperação após um exercício ou como a quantidade 
de oxigênio consumida durante a recuperação acima daquela que teria sido consumida normalmente em repouso, em mesmo período de tempo. Durante a recuperação após um exercício, a demanda de energia é consideravelmente menor, porque o exercício já cessou. Entretanto, o consumo de oxigênio continua em nível relativamente alto por certo período de tempo; a magnitude depende da intensidade e, em menor grau, da duração do exercício. (FOSS, 2000)

O conceito de dívida de oxigênio, como elaborado originalmente por Hill em 1922, significava que o oxigênio consumido durante a recuperação era utilizado principalmente para restaurar a condição pré-exercício do corpo, incluindo o reabastecimento das reservas de energia que haviam sido depletadas e a remoção de todo o lactato que se acumulara durante o exercício. Muitos interpretam erroneamente o termo clássico "dívida de oxigênio", classificando-o como o oxigênio extra consumido durante a recuperação, que é utilizado para repor o oxigênio cedido durante o exercício. (FOSS, 2000)

Durante os primeiros dois ou três minutos de recuperação, o consumo de oxigênio declina muito rapidamente; a seguir, mais lentamente até vir a alcançar ritmo constante, equivalente ao nível de repouso. A fase inicial da recuperação é identificada como componente rápido, e a fase mais lenta é designada como componente lento. (FOSS, 2000) Hill et al. atribuíram que a fase rápida do $\mathrm{VO}_{2}$ após o exercício era promovida pela remoção oxidativa do lactato nos músculos onde era formado, e, durante a fase lenta, ocorria a remoção oxidativa do lactato por difusão nos músculos. (GAESSER,1984)

O consumo elevado de oxigênio durante o componente rápido da recuperação inclui o oxigênio que atende à necessidade energética pós-exercício de: restauração da mioglobina com oxigênio, restauração dos níveis sangüíneos de oxigênio, o custo energético da ventilação elevada, atividade cardíaca elevada e, provavelmente, o reabastecimento dos fosfagênios (ATP e CP). O consumo elevado de oxigênio durante o componente lento da recuperação está associado a inúmeros eventos fisiológicos, incluindo: a temperatura corporal elevada envolvendo o efeito $\mathrm{Q}_{10}$; o custo em oxigênio da ventilação; o custo em oxigênio da maior atividade do miocárdio; o aumento nas atividades da bomba de sódio e do potássio; a ressíntese do glicogênio; o efeito calorigênico das catecolaminas; a oxidação do lactato, entre outros fatores. Hagberg et al. afirmam que a maior parte $(60 \%$ a $70 \%)$ do consumo de oxigênio do componente lento pode ser atribuída ao efeito da temperatura sobre o metabolismo. (FOSS, 2000)

A magnitude do volume do componente rápido está relacionada com a intensidade submáxima do exercício, porém não com a duração do exercício. As medidas de ventilação-minuto da produção de dióxido de carbono e da captação de oxigênio estão elevadas após a realização do exercício com intensidade mais 
alta. Entretanto, parece haver um limite para o efeito que a intensidade do exercício exerce sobre o aumento do componente rápido do oxigênio de recuperação, pois o componente rápido, após exercício de curta duração e de intensidade supramáximo, é semelhante a outras intensidades de trabalho. (FOSS, 2000) Margaria et al concluíram que o rápido declínio do $\mathrm{VO}_{2}$ após o exercício relaciona-se com a formação do lactato, que é resultado de várias fosfatagens no músculo esquelético. (GAESSER, 1984)

Certas determinações dos sistemas metabólicos feitas durante a componente lento não são afetadas após a realização do trabalho com maior intensidade. A combinação da intensidade mais alta e da maior duração aumenta o componente lento 5 vezes acima daquele medido após período mais curto, com a mesma intensidade. O componente lento não é afetado por mudança na intensidade ou na duração do exercício até ser apresentado um limiar de estímulo combinado de intensidade versus duração. (FOSS, 2000)

\section{Anaeróbico}

A adenosina trifosfato é a energia comum utilizada para todo o trabalho biológico que ocorre dentro das células. A energia útil obtida após a quebra do ATP para adenosina difosfato (ADP) e fosfato inorgânico (Pi) é a energia utilizada para a contração do músculo esquelético durante o exercício de curta duração. Além da ATP, o músculo esquelético possui outro fosfato altamente energético, chamado creatina fosfato (CP), que pode ser utilizado na ressíntese de ATP. (WOLINSKY, 2002; STRYER, 1996)

O sistema ATP-CP envolve o armazenamento de ATP e CP em fibras do músculo esquelético. Dependendo do tipo de fibra muscular e do estado de treino, a concentração de $\mathrm{CP}$ no músculo esquelético é de 3 a 5 vezes superior àquela da ATP. O sistema ATP-CP é anaeróbico, e a quebra ATP e CP ocorre se o oxigênio estiver ou não disponível. Esse sistema fornece a fonte mais prontamente disponível de ATP para contração muscula Y,2002)

O sistema do ácido láctico é anaeróbico, no qual a ATP é produzida no músculo esquelético por meio da glicólise. A ATP é gerada pela hidrólise da glicose (glicólise) ou do glicogênio (glicogenólise) armazenado no músculo a duas moléculas de lactato. Esse sistema fornece a energia da ATP para exercício extenuante de alta intensidade quando o suprimento de oxigênio é inadequado ou a demanda de energia do exercício é maior que a capacidade do sistema aeróbico para prover ATP. O sistema ATP-CP é de grande importância, pois pode prover energia para a contração muscular por período breve de tempo. Sem a produção anaeróbica rápida de $\mathrm{ATP}$, ocorreria fadiga do músculo esquelético muito rapidamente. (WOLINSKY, 2002) 
O sistema aeróbico requer oxigênio para a quebra de glicose a piruvato e a subseqüente degradação a $\mathrm{CO}_{2}$ e $\mathrm{H}_{2} \mathrm{O}$ por meio do ciclo tricarboxílico e do transporte pelo sistema de elétrons. O sistema aeróbico é muito mais eficiente para a produção de ATP quando comparado ao do ácido láctico. (WOLINSKY, 2002)

\section{Bioquímica dos nutrientes}

\section{Carboidratos}

No exercício de alta intensidade, a maioria da demanda energética é suprida pela energia que se torna disponível pela degradação dos carboidratos. No exercício de intensidade moderada e de duração prolongada, o desempenho comumente é limitado pela disponibilidade dos carboidratos como combustível. Conseqüentemente, o suprimento de carboidratos e seu metabolismo são fundamentais para a capacidade de trabalho físico. (MAUGHAN, 2000)

O ATP é o único elemento químico usado pelo corpo para realizar as funções fisiológicas e o trabalho. Os monossacarídeos são absorvidos pelo intestino delgado e dirigem-se ao fígado, onde são transformados em glicose. A seguir, a glicose é armazenada no fígado como glicogênio ou é lançada no sangue. Depois, a glicose sangüínea pode ser usada e captada pelas células ou, se necessário, armazenada como glicogênio intramuscular. Essas duas formas de carboidratos, glicose e glicogênio, funcionam como importantes combustíveis que entram nos processos metabólicos celulares pela glicólise anaeróbica ou aeróbica. Por meio dessas vias, os carboidratos que ingerimos resultam em ATP. A única diferença entre elas reside no fato de ser ou não fornecido oxigênio durante determinada atividade capaz de inibir o acúmulo de lactato pelo desvio do ácido pirúvico para as vias aeróbicas. (FOSS, 2000)

Os níveis sanguiíneos de glicose são mantidos principalmente pelo glicogênio armazenado no fígado. Quando a glicose sangüínea é baixa ou quando há exercício prolongado no qual os músculos esqueléticos o estão utilizando como combustível - substrato, o glicogênio proveniente do fígado é fracionado para glicose por processo denominado glicogenólise. O glicogênio do hepático é desdobrado à glicose-6-fosfato, que, por sua vez, é hidrolisada para originar glicose. A liberação de glicose do fígado pela degradação do glicogênio reabastece o estoque de glicose no sangue. (CAMPBEL, 2001) Ocorre exatamente o oposto quando a glicose sangüínea é alta, como acontece após uma refeição. A glicose é captada pelos tecidos com a ajuda de hormônio denominado insulina, que é liberado pelo pâncreas. Quando é captado pelo fígado, a glicose pode ser usada pelo 
metabolismo ou pode ser convertida para glicogênio por meio de processo denominado glicogênese. (FOSS, 2000)

Embora a glicose plasmática seja um importante substrato energético, durante o exercício submáximo prolongado, deve ser enfatizado que as reservas iniciais de glicogênio no músculo esquelético são as determinantes primárias da habilidade de o indivíduo manter o exercício moderado ou pesado prolongadamente. $\mathrm{O}$ depósito de glicogênio no músculo é amplamente dependente do nível de condicionamento físico e do estado agudo e prolongado da nutrição à base de carboidratos. Os músculos esqueléticos treinados possuem depósitos maiores de glicogênio que são depletados em freqüência menor durante o exercício. A manipulação da ingestão de carboidratos pela dieta antes, durante e depois do exercício pode melhorar largamente o desempenho do exercício por meio da otimização dos depósitos de glicogênio hepático e muscular ou pela manutenção da homeostase da glicose sangüínea. (LIEBMAN; WILKINSON capud WOLINSKY, 2002)

A principal função dos carboidratos consiste em funcionar como combustível energético, particularmente durante o exercício. A ingestão diária de carboidratos deve ser suficiente para manter as reservas corporais de glicogênio, que são relativamente limitadas. Por outro lado, uma vez alcançada a capacidade de a célula armazenar glicogênio, os açúcares em excesso são transformados em gordura e armazenados nesta forma. Daí resulta o fato de o conteúdo corporal de gordura aumentar quando são consumidas quantidades excessivas de carboidratos, até mesmo quando a dieta é pobre em gorduras. (McARDLE, 1998)

\section{Lipídios}

Os lipídios representam a maior reserva nutritiva de energia química para a realização de trabalho biológico, incluindo a contração muscular. Os depósitos de lipídios no tecido adiposo provêem o isolamento do frio e protegem os órgãos vitais. Os lipídios dietéticos também atuam como transportadores de vitaminas lipossolúveis: A, D, E e K. (MAUGHAN, 2000)

Os ácidos graxos representam a fonte predominante de combustível para a produção aeróbica de ATP em repouso e durante atividade de leve a moderada. O colesterol não pode ser usado pelo corpo como fonte de combustível. Consequientemente, uma pessoa com nível total elevado de colesterol não conseguirá reduzi-lo apenas por meio do exercício. (FOSS, 2000)

Antes de os ácidos graxos serem metabolizados, deverão ser separados da molécula de triglicerídeos por processo denominado lipólise. Esta é realizada pela enzima lípase, sensível aos hormônios, que está presente em grandes 
quantidades nos adipócitos e que é influenciada pela adrenalina e pela noradrenalina. As concentrações plasmáticas de adrenalina e de cortisol também aumentam à medida que o exercício progride. (MAUGHAN, 2000) Durante os exercícios, a concentração de ácidos graxos livres no sangue poderá aumentar oito vezes. Após terem penetrado no músculo esquelético, os ácidos graxos são ativados à custa de um ATP. A seguir, por meio do processo de beta-oxidação, os compostos com dois carbonos são separados a fim de que sejam transformados em acetilCoA para sua penetração no Ciclo de Krebs. (FOSS, 2000) A degradação de ácidos graxos na matriz mitocondrial ocorre pela remoção sucessiva de duas unidades de carbono na forma de acetil-CoA. Cada clivagem de uma porção de dois carbonos requer uma seqüência de reações com quatro etapas, designada beta-oxidação. A oxidação completa de ácidos graxos pelo ciclo do ácido cítrico e pela cadeia transportadora de elétrons libera grandes quantidades de energia. (CAMPBELL, 2001)

O principal problema associado à utilização de lipídios como combustível para a realização de exercícios não é a disponibilidade física dos lipídios como fonte energética, mas a velocidade com que podem ser captados pelo músculo e oxidados para prover energia. Essa limitação significa que a oxidação da gordura somente pode suprir ATP numa taxa suficiente para manter o exercício numa intensidade de aproximadamente $60 \%$ da $\mathrm{VO}_{2}$ máx. Para gerar ATP que mantenha exercícios de maior intensidade, os carboidratos devem ser utilizados (MAUGHAN, 2000).

O treinamento com exercícios exerce um efeito profundo sobre o metabolismo dos gorduras durante o exercício. A maior mobilização e utilização de gorduras com o treinamento ajuda a conservar as reservas relativamente limitadas de glicogênio nos músculos ativos. Essa adptação no músculo esquelético com o treinamento através de exercícios pode representar o resultado de:

- maior quantidade de enzimas envolvidas na beta-oxidação, metabolismo do Ciclo de Krebs e a cadeia tranportadora de elétrons;

- transporte aprimorado dos ácidos graxos pela membrana plasmática (sarcolema) da fibra muscular;

- aumento do transporte de ácidos graxos dentro da célula muscular pela ação da carnitina e carnitina-transferase;

- proliferação de capilares nos músculos treinados, o que se reflete tanto por maior número total quanto por maior densidade desses microvasos.

O aprimoramento na produção aeróbica de ATP pelas gorduras com o treinamento aeróbico pode ajudar a manter a integridade celular assim como o 
alto nível de função que poderia contribuir para o aperfeiçoamento da endurance independente das reservas de glicogênio. (McARDLE, 1998)

\section{Proteína}

O metabolismo da proteína durante o exercício é um aspecto particular, pois está relacionado a fatores, como: intensidade, duração, modalidade do exercício, meio ambiente do treinamento, nível de ingestão protéica e energética, a idade e o sexo do indivíduo. A obtenção de energia a partir dos aminoácidos envolve a remoção do grupo amino. Isso deixa um produto que sofre transformação adicional antes de penetrar no Ciclo de Krebs para produzir energia de maneira semelhante aos carboidratos a aos ácidos graxos. Além disso, 18 aminoácidos foram identificados como glicogênicos; a leucina, a isoleucina e a valina são os mais prontamente disponíveis e podem ser metabolizados nos músculos. (FOSS, 2000)

O débito da alanina do tecido musculoesquelético no sangue aumenta com o exercício e proporcionalmente à sua intensidade. A explicação para esse aumento, inicialmente, constituiu problema, uma vez que, no tecido musculoesquelético, não há proteínas ricas em alaninas para servir como fonte. Além disso, o precursor poderia não ser uma proteína típica com balanço variado de aminoácidos porque esta variedade poderia ser observada no débito. (HICKSON JR.; WOLINSKY capud WOLINSKY, 2002)

A hipótese da síntese de alanina induzida pelo exercício é a de servir a transportadores hidrossolúveis, não tóxicos de aminoácidos produzidos por catabolismo protéico. O transportador, a alanina, move esses grupos para fora dos tecidos e previne a formação de moléculas tóxicas de amônia. Uma vez no sangue, o transportador é captado pelo fígado, onde a "carga" do aminoácido é perdida para o ciclo da uréia com a formação de uréia. O ciclo da uréia catalisa a conversão dos grupos amino em uréia e, por isso, impede os efeitos potencialmente nocivos de aumento de concentração de amônia livre. (MAUGHAN, 2000) O que permanece é o esqueleto carbônico do transportador, que é convertido a glicose pela gliconeogênese. A glicose é liberada do fígado para a corrente sangüínea, e o músculo esquelético efetua sua captação durante a circulação. Para completar o ciclo, a glicose "fresca" no músculo esquelético, captada do sangue, é convertida a piruvato e, então, é transaminada para formar alanina novamente. (HICKSON JR.; WOLINSKY capud WOLINSKY, 2002)

Deve-se reconhecer que o ciclo da glicose alanina pode não resultar na formação de aumento líquido na glicose sangüínea para captação no músculo esquelético. Novamente, ocorre a hipótese de que a finalidade do ciclo seja o movimento de agrupamentos de amônia, tóxicos para o exterior do organismo. 
Entretanto, há outro benefício indireto que permite o catabolismo de aminoácidos no tecido musculoesquelético e que pode fornecer energia para o trabalho. A questão é se este catabolismo é significativo ou não em termos das necessidades protéicas da dieta. (HICKSON JR.; WOLINSKY capud WOLINSKY, 2002)

A desintegração protéica acima do nível de repouso ocorre durante o exercício com treinamento tanto de endurance quanto de resistência, em grau maior do que se acreditava antigamente. Isso é mais evidente quando as reservas de carboidratos e/ou energia são baixas. O maior padrão de catabolismo protéico durante o exercício de endurance e o treinamento intensivo espelha, com freqüência, a mistura metabólica que vigora durante a inanição de curta duração. Com as reservas de glicogênio depletadas, a produção de glicose pelo fígado é mantida, essencialmente, pelo processo da gliconeogênese. É provável que a maior desintegração de proteína possa refletir a tentativa de o corpo fornecer glicose para o funcionamento do sistema nervoso central. Essas observações comprovam a importância da dieta rica em carboidratos como meio de conservar a proteína muscular para os atletas que participam de treinamento prolongado e intensivo. (McARDLE, 1998)

\section{Intensidade do exercício}

\section{$\mathrm{VO}_{2}$ máx. e FCM}

$\mathrm{O}$ valor do $\mathrm{VO}_{2}$ máx. expressa, quantitativamente, a capacidade individual para a ressíntese aeróbica do ATP. Assim, trata-se de fator importante para determinar a capacidade individual em realizar exercício de alta intensidade por mais de 4 ou 5 minutos. A capacidade de alcançar um $\mathrm{VO}_{2}$ máx. alto comporta significado fisiológico importante além de seu papel em apoio ao metabolismo energético constante, pois a alta capacidade aeróbica requer resposta integrada e de alto nível de diversos sistemas fisiológicos coadjuvantes. (McARDLE, 1998)

Para cada pessoa, a freqüência cardíaca e a captação de oxigênio tendem a relacionar-se linearmente durante ampla gama de exercícios aeróbicos. Se essa relação precisa for conhecida, a freqüência cardíaca do exercício poderá ser usada para estimar a captação de oxigênio durante as formas semelhantes de atividade física. Um dos principais problemas consiste em determinar o grau de semelhança entre o teste laboratorial usado para estabelecer a linha de freqüência cardíacacaptação de oxigênio e a atividade específica na qual é aplicada. Por um lado, outros fatores, além da captação de oxigênio, podem influenciar a resposta da frequiência cardíaca ao exercício, pois incluem temperatura ambiente, emoções, ingestão prévia de alimentos, posição corporal, grupos musculares exercitados, 
continuidade do exercício e a contração estática ou dinâmica dos músculos. Apesar de a técnica que consiste em utilizar a freqüência cardíaca para estimar o dispêndio energético ser prática, poderá ter indicações limitadas com finalidades de pesquisa, pois sua validade ainda não foi devidamente estabelecida, a não ser em poucas atividades gerais. (McARDLE, 1998)

Durante o exercício leve, há aumento gradual na quantidade absoluta de oxidação de gorduras à medida que progride o exercício de resistência aeróbica. Nessa situação, os ácidos graxos podem servir como fonte primária de combustível que permite atividade muito prolongada, como andar, mesmo no estado de jejum. A utilização máxima de ácidos graxos no indivíduo não treinado pode ocorrer em cerca de $50 \%$ do $\mathrm{VO}_{2}$ máx. Há relação direta entre a intensidade do exercício e a dependência no glicogênio muscular como substrato energético. Em intensidades muito altas de exercício, o transporte de oxigênio para o trabalho muscular pode não satisfazer a demanda do metabolismo oxidativo necessitando, assim, de solicitação maior de carboidratos para energia. (WOLINSKY, 2002)

A intensidade do exercício também se encontra diretamente relacionada à captação de glicose na circulação pelo músculo, bem como o débito de glicose hepática. Assim, um aumento nas taxas de trocas respiratórias (TTR) com aumento na intensidade do exercício resulta em aumento na taxa da glicogenólise hepática e muscular, com o objetivo de suprir as necessidades glicolíticas séricas. $\mathrm{O}$ aumento da captação da glicose pela contração muscular pode ser atribuído ao aumento no fluxo sangüíneo muscular e à eficiência da extração de glicose pelo músculo. (WOLINSKY, 2002)

\section{GLUT-4}

A perda da massa muscular é característica do estado diabético ou do jejum ou consequiência de inatividade física prolongada. O desenvolvimento ou a atrofia do músculo esquelético dependem do balanço entre a taxa de síntese e a taxa de degradação das proteínas intracelulares. (KIMBALL, et al capud LUCIANO, 1998)

As ações da insulina sobre o metabolismo das proteínas e dos aminoácidos são orientadas no sentido do anabolismo. A insulina, após interação com o receptor de membrana, estimula os transportadores de glicose (GLUT-4), facilita a entrada de carboidratos para a célula e exerce ação anabólica sobre o metabolismo protéico pelos seguintes mecanismos: estimulando o transporte de aminoácidos para dentro da célula; aumentando, ao nível ribossômico, a eficiência do processo de tradução; atuando na etapa de iniciação da síntese protéica. (O'BRIEN \& GRANNER, capud LUCIANO, 1998) 
Em organismos treinados, pode-se observar que há sensibilidade das células musculares e adiposas à insulina, relacionada com o aumento no número de transportadores de glicose insulino - sensíveis (GLUT-4) nas membranas celulares e túbulos transversos dos músculos. Os mecanismos envolvidos na maior translocação dos GLUTs para as superfícies celulares, secundária ao treinamento físico, ainda não foram esclarecidos, porém, segundo Lund, citado por Luciano (1998), esses transportadores pertencem ao mesmo "pool" de transportadores responsivos à insulina. Esse efeito pode estar ligado à hipóxia e/ou ao aumento do fluxo sangüíneo muscular durante a atividade física. Sabe-se que, em situações em que a produção de glicose é diminuída, ocorre a "up regulation" dos receptores, um dos fatores que explicam a maior sensibilidade ao hormônio. Além disso, o treinamento físico também aumenta a atividade tirosina-quinase dos receptores de insulina nos músculos esqueléticos e promove maior captação de glicose ao favorecer o metabolismo energético e minimizar complicações em outros sistemas interdependentes. (DOHM et al capud LUCIANO, 1998; SANTOS, 1989) A atividade contrátil mobiliza um "pool" de transportadores de glicose independente da insulina, o que pode contribuir para melhoria nos níveis glicêmicos.

\section{Gliconeogênese}

A gliconeogênese é uma via metabólica muito importante porque o cérebro é altamente dependente de glicose como alimento primário. Também as hemácias necessitam de glicose. Em período maior de jejum, a glicose deve ser formada por fontes não glicídicas para a manutenção da glicemia. A gliconeogênese é também importante durante períodos de exercício intenso. (STRYER, 1996)

A via gliconeogênica transforma piruvato em glicose. Os precursores não glicídicos da glicose entram, principalmente, como piruvato, oxaloacetato de dihidroxiacetona fosfato. Os principais precursores não glicídicos são lactato, aminoácidos (BCAA's) e glicerol. O lactato é formado pelo músculo esquelético ativo quando a velocidade de glicólise excede a taxa metabólica do ciclo do ácido cítrico e da cadeia respiratória. (STRYER, 1996) Os aminoácidos são derivados das proteínas da dieta e, durante o jejum, da degradação de proteínas do músculo esquelético. (DEVLIN, 1998) A hidrólise de triacilgliceróis em células adiposas produz glicerol e ácidos graxos. O glicerol é um precursor da glicose, mas os animais não podem transformar ácidos graxos em glicose. O metabolismo de ácidos graxos é eficazmente controlado de modo que a síntese e a degradação respondem bem às necessidades fisiológicas. A acetil-CoA não pode ser transformada em piruvato ou oxaloacetato em animais. Os dois átomos de carbono da acetila da acetil-CoA entram no ciclo do ácido cítrico, mas saem dois átomos 
de carbono do ciclo nas descarboxilações catalisadas pela isocitrato desidrogenase e pela alfa-cetoglutarato desidrogenase. Em consequiência, o oxaloacetato é regenerado, mas não é formado de novo quando a unidade acetila da acetil-CoA é oxidada pelo ciclo do ácido cítrico. (STRYER, 1996)

O local principal de gliconeogênese é o fígado. A gliconeogênese também ocorre no córtex dos rins, mas a quantidade total de glicose formada é em torno de um décimo da formada no fígado, em decorrência da menor massa dos rins. Pouca gliconeogênese ocorre no cérebro, no músculo esquelético ou cardíaco. Entretanto, a gliconeogênese hepática e renal ajuda a manter a glicemia para que o cérebro e o músculo possam extrair glicose suficiente para atender a suas demandas metabólicas. (STRYER, 1996)

\section{Gasto calórico após atividade física - EPOC}

O termo dívida (débito) de oxigênio foi cunhado originalmente pelo cientista Prêmio Nobel Archibalb Vivin Hill, em 1922. A.V. Hill, assim como outros, abordou o metabolismo energético durante o exercício e a recuperação em termos de justificativa financeira. De acordo com essa estrutura, as reservas corporais de carboidratos eram comparadas a "créditos" de energia. Se esses créditos acumulados eram gastos durante o exercício, contraía-se uma "dívida": quanto maior era o "déficit de energia", maior seria a dívida de energia contraída. Admitiase que a captação de oxigênio para a recuperação representava o custo metabólico destinado a pagar essa dívida, daí o termo "débito de oxigênio". (McARDLE, 1998)

O acúmulo de lactato durante o componente anaeróbico do exercício representava a utilização de glicogênio. Acreditava-se que o débito de oxigênio subseqüente desempenhava duas finalidades: restabelecer as reservas originais de glicogênio para ressíntese de, aproximadamente, $80 \%$ do lactato transformandoo novamente em glicogênio no fígado pelo Ciclo de Cori e catabolizar o lactato restante pelo ácido pirúvico no ciclo de Krebs. O ATP gerado nesse processo era usado presumivelmente para acionar a ressíntese de lactato para glicogênio. (McARDLE, 1998)

Em 1933, após o trabalho de Hill, os pesquisadores de Harvard Fatigue Laboratory explicaram suas observações sobre a porção inicial da captação de oxigênio da recuperação consumida antes do lactato sangüíneo começar a diminuir. Era possível contrair uma dívida de oxigênio de quase 3 litros sem acúmulo apreciável de lactato. Para explicar esses achados, foram propostas duas fases para o débito de oxigênio: débito de oxigênio aláctico e débito de oxigênio láctico associado aos níveis sangüíneos elevados de lactato. (McARDLE, 1998) 
A dívida aláctica é para a recuperação após exercício leve em ritmo estável ou para a fase rápida da recuperação após exercício mais extenuante. Era atribuída à restauração dos fosfatos de alta energia $\mathrm{ATP}$ e $\mathrm{CP}$ depletados durante o exercício. Argumentava-se que a energia para essa restauração provinha do fracionamento dos nutrientes alimentares durante a recuperação. A dívida láctica, em concordância com a explicação de A. V. Hill, representava a conversão de lactato para glicogênio no fígado.

Para aceitar a explicação tradicional sobre a fase láctica da dívida de oxigênio, deve ser estabelecido que a maior parte do lactato acumulado durante o exercício é ressintetizado para glicogênio durante a recuperação, como havia sido especulado por Hill e outros. Isso nunca foi comprovado. Aparentemente, a maior parte do lactato é oxidado para a produção de energia. Isso parece provável, pois coração, fígado, rim e músculo esquelético utilizam prontamente o lactato como substrato energético durante o exercício e a recuperação. (McARDLE, 1998)

Não há dúvida de que o metabolismo aeróbico elevado na recuperação é necessário para restaurar o corpo a sua condição de pré-exercício e resulta, especialment,e dos eventos metabólicos e citológicos precedentes ocorridos durante o exercício. Em exercício de curta duração de leve a moderado, a captação de oxigênio da recuperação serve para refazer os fosfatos de alta energia depletados pelo exercício; esse processo é rápido e é completado em poucos minutos. Durante exercício aeróbico de alta intensidade e de maior duração, a captação de oxigênio da recuperação pode continuar elevada por período consideravelmente maior; a esse processo damos o nome de EPOC - consumo excessivo de oxigênio após o exercício. (McARDLE, 1998)

Durante o exercício exaustivo com componente anaeróbico significativo e acúmulo de lactato, parte da captação de oxigênio da recuperação é usada para a ressíntese da porção do lactato, transformando-o novamente em glicogênio. Entretanto, a principal fonte para reabastecer o glicogênio é representada pelos carboidratos dietéticos e não pelo lactato ressintetizado. (McARDLE, 1998)

O débito de oxigênio consideravelmente maior em relação ao déficit de oxigênio durante o exercício aeróbico prolongado representa o processo fisiológico que ocorre durante a recuperação. Por exemplo, a temperatura corporal sobe cerca de $3^{\circ} \mathrm{C}$ durante longa sessão de exercícios aeróbicos vigorosos e pode permanecer elevada por várias horas durante a recuperação. Isso exerce efeito estimulante direto sobre o metabolismo, acarretando aumento na captação de oxigênio da recuperação. A dívida de oxigênio ou, mais precisamente, a captação de oxigênio da recuperação e o consumo excessivo de oxigênio após o exercício (EPOC) refletem tanto o metabolismo anaeróbico do exercício prévio quanto as ajustagens respiratórias, circulatórias, hormonais, iônicas e térmicas que ocorrem 
durante a recuperação. (McARDLE, 1998)

As causas do EPOC como resultado de exercício intenso podem ser:

- ressíntese de ATP e CP;

- ressíntese de lactato para glicogênio;

· oxidação de lactato no metabolismo energético;

- restauração do oxigênio no sangue;

- efeitos termogênicos da temperatura central elevada;

- efeitos termogênicos dos hormonios, particularmente das catecolaminas adrenalina e noradrenalina;

- efeitos da freqüência cardíaca elevada, ventilação e outros níveis elevados da função fisiológica. (McARDLE, 1998)

\section{Conclusões}

Em 1920, Meyerhof identificou que o precursor do lactato era o glicogênio muscular. Observou que, quando o lactato apresentava-se no músculo, o glicogênio sempre desaparecia em quantidade correspondente, $\log$ a maioria do lactato formado durante a contração é retornada a glicogênio na recuperação.

Ainda não foi bem aceita a teoria do débito de $\mathrm{O}_{2}$ pós-exercício, pois há dois problemas: quais os fatores responsáveis pelo elevado $\mathrm{VO}_{2}$ pós-exercício e como este fenômeno pode ser chamado. $\mathrm{O}$ débito de oxigênio foi definido como quantidade total de oxigênio usado, após cessar o exercício, na recuperação. Hill e Lupton levantaram a hipótese de que a elevação do $\mathrm{VO}_{2}$, depois do exercício, era para a reparação do déficit de $\mathrm{O}_{2}$, que havia sido contraído durante o exercício.

A temperatura talvez seja o fator mais importante para a elevação do $\mathrm{VO}_{2}$ pós-exercício; isso é relatado para os efeitos da elevada temperatura na energia mitocondrial. Como conseqüência, maior consumo de oxigênio pode ser requerido para oferecer quantidade de ATP a ser sintetizado.

$\mathrm{O}$ uso do termo "débito de $\mathrm{O}_{2}$ ” possui várias limitações. A terminologia é importante resultado; como o nome sugere, é uma relação de causa e efeito quando é aplicada a algo. Esta é a posição em que o termo "débito de $\mathrm{O}_{2}$ " pode não ser usado: implica uma causalidade que é contrariamente ao que se conhece sobre o metabolismo pós-exercício. 


\section{Referências}

CAMPBELL, Mary K. Bioquímica. 3. ed. São Paulo: Artmed, 2001.

DEVLIN, T. M. Manual de bioquímica com correlações clínicas. 4. ed. São Paulo: Edgard Blucher, 1998.

FOSS, Merle L., KETEYIAN, Steven J., FOX. Bases fisiológicas do exercício e do esporte. 6. ed. Rio de Janeiro: Guanabara Koogan, 2000.

GAESSER, Glenn A., BROOKS, George A. Metabolic bases of excess post-exercise oxygen consumption: a review. Los Angeles, 1984.

GORE, C.J. Withers, R.T. Effect of exercise intensity and durantion on postexercise metabolism. Austrália, 1990.

LUCIANO, E; MELLO, M.A. R. Atividade física e metabolismo de proteínas em músculos de ratos diabéticos experimentais. Ver. Paul. Educ. Fís. 12(2): 2002209, 1998.

MAUGHAN, Ron, GLEESON, Michael, GREENHAFF, Paul L. Bioquímica do exercício e do treinamento. São Paulo: Manole, 2000.

McARDLE, William D., KATCH, Frank I., KATCH, Victor L. Fisiologia do exercício energia, nutrição e desempenho humano. 4. ed. Rio de Janeiro: Guanabara Koogan, 1998.

STRYER, Lubert. Bioquímica. 4. ed. Rio de Janeiro: Guanabara Koogan, 1996.

WOLINSKY, Ira, HICKSON Jr. James F. Nutrição no exercício e no esporte. 2. ed. São Paulo: Roca, 2002. 